\title{
Relevance of Established Risk Factors for Carcinoma Breast in Indian Women
}

\author{
Shaifali Mahajann ${ }^{1}$, Christeena Geneev ${ }^{2}$, Vivek Immanuel ${ }^{3}$, Pamela Alice Kingsley ${ }^{4}$ \\ ${ }^{1}$ Department of Radiation Oncology, Christian Medical College and Hospital, Ludhiana, Punjab, \\ India. ${ }^{2}$ Landour Community Hospital, Mussoorie, Uttarakhand, India. ${ }^{3}$ Department of Radiation \\ Oncology, Christian Medical College and Hospital, Ludhiana, Punjab, India. ${ }^{4}$ Department of \\ Radiation Oncology, Christian Medical College and Hospital, Ludhiana, Punjab, India.
}

\section{ABSTRACT}

\section{BACKGROUND}

Breast cancer is the most common cancer in women of India and across the globe. More than 2.1 million women were diagnosed to have breast cancer in 2018 worldwide. An incremental trend in incidence and mortality has been observed in South-Asian, low to middle income, developing countries. Age adjusted incidence in India is 25.8 per 100,000 women in India. The established risk factors for causation of carcinoma breast have been deduced primarily from Western studies and their applicability to Indian women remains varied. We wanted to evaluate the relevance of the established risk factors for carcinoma breast in patients presenting to our institute.

\section{METHODS}

This case-control study included 65 patients with histologically confirmed diagnosis of carcinoma breast in the test group and 65 healthy women in the control group. All enrolled women were made to fill a questionnaire to assess for presence or absence of established risk factors in them. Results were obtained by calculating percentage of women with these risk factors in both arms.

\section{RESULTS}

Among the established factors for carcinoma breast, $18.4 \%$ patients in the test group were obese compared to $12.3 \%$ women in the control group. This difference was found to be statistically significant with a $\mathrm{p}$ value of $<0.02$. However, there was no significant relevance between the two compared groups with respect to other risk factors studied.

\section{CONCLUSIONS}

While the established risk factors for carcinoma breast have been found to be relevant in multiple national and international studies, their applicability to specific populations such as those catered to by our institution varied. Out of all the established risk factors for carcinoma breast in the western population, the present study suggested significance only for obesity, with a BMI of $\geq 30 \mathrm{Kg} / \mathrm{m}^{2}$

\section{KEY WORDS}

Breast Cancer, Risk Factors, Relevance, Indian, Established
Corresponding Author: Shaifali Mahajan, 12-A, Tagore Colony, Lawrence Road, Amritsar-143001, Punjab, India.

E-mail: shaifalimahajan1991@gmail.com

DOI: $10.14260 / \mathrm{jemds} / 2020 / 463$

How to Cite This Article:

Mahajan S, Geneev C, Immanuel V, et al. Relevance of established risk factors for carcinoma breast in Indian women. J. Evolution Med. Dent. Sci. 2020;9(30): 21242128, DOI: $10.14260 /$ jemds/2020/463

Submission 09-03-2020,

Peer Review 18-06-2020,

Acceptance 24-06-2020,

Published 27-07-2020.

Copyright (c) 2020 JEMDS. This is an open access article distributed under Creative Commons Attribution License [Attribution 4.0 International (CC BY 4.0)] 


\section{BACKGROUND}

As per World Health Organization 2018 statistics, noncommunicable diseases claim 41 million lives every year, equivalent to $71 \%$ of all deaths globally. Cancer is emerging as one of the most important health issues worldwide, with cancer related incidence and mortality growing rapidly. It is expected to rank as the leading cause of death and the single most important barrier to increasing life expectancy in every country of the world in the 21st century. ${ }^{1}$ According to Globocan 2018, an estimated 18.1 million new cases and 9.6 million cancer deaths occurred in 2018. ${ }^{1}$ This figure is expected to rise to 11 million deaths by the year 2030.2

Carcinoma of breast is the second most common cancer overall and the most common cancer in women worldwide. ${ }^{3}$ It accounts for $11.6 \%$ of all cancer related mortality, being second only after carcinoma lung. ${ }^{1}$ More than 2.1 million women were diagnosed to have breast cancer in 2018 accounting for about 1 in 4 women in the western world. 4

A shifting trend towards increasing incidence of breast cancer in developing countries is occurring, with middle and low income countries accounting for most of the breast cancer related deaths globally. ${ }^{5}$ Out of the total cancer related deaths worldwide, Asia accounts for $57.3 \%$ of total. ${ }^{1}$ Regions such as South America, Africa and Asia where the incidence was significantly low until recently, now show a tremendous rise. 6 This transition can be attributed to a combination of demographic and social/ economic factors or westernization of lifestyle.7,8

Breast cancer is now ranked number one cancer in women of India leaving behind cervical cancer. According to Globocan 2012, India and China collectively account for one-third of global breast cancer burden. Age-adjusted incidence rate for Indian women is as high as 25.8 per 100,000 and mortality rate is 12.7 per $100,000 .{ }^{9}$ India experienced a $11.54 \%$ increase in incidence and $13.82 \%$ increase in breast cancer mortality between the years 2008 to 2012.3,10 Most cases are diagnosed at a locally advanced or metastatic stage and hence is a cause of significant morbidity and mortality.

Various modifiable and non-modifiable factors have been attributed to the causation of breast cancer. ${ }^{11}$ Advancing age, menarche at $<12$ years, menopause at $>54$ years, nulliparity, age $>30$ years at the time of first pregnancy, family history of cancer, previous history of benign breast disease such as atypical hyperplasia, obesity, smoking, alcoholism, use of hormone replacement therapy are some of the established risk factors for carcinoma breast. Breast-feeding, regular physical activity and healthy lifestyle on the contrary are considered as protective against breast cancer.

The relevance of these risk factors in breast cancer causation in women of European and American ancestry is well established in various studies. But the bearing of these factors in Indian population who are diverse in terms of geography, ethnicity, culture, dietary habits and access to medical continues to remain a matter of uncertainty. Better understanding of the risk factors specifically in our population is pertinent for optimum screening and treatment. Hence, in this current study, we sought to evaluate the applicability of the established risk factors for carcinoma breast in patients presenting to our institute.

\section{METHODS}

This single-centre, hospital-based, case-control study was conducted from January 5, 2019 to August 4, 2019 in the Department of Radiation Oncology, Christian Medical College \& Hospital, Ludhiana included 130 women aged 40 to 80 years. The study design was approved by the ethics and research committee of the institute. Women were enrolled in the study after taking written informed consent, which included 65 patients of carcinoma breast on follow-up in Radiation oncology OPD taken in the test group and 65 healthy women from the community in the control group. We see an approximate of 140 breast cancer patients in OPD every year, of which around 120 patients (i.e. 85-87\%) are previously diagnosed and treated cases who visit for follow-up. We included these follow-up patients in our study over a period of 7 months. Of approximately 70 follow-up patients seen in this duration, 65 consented for enrolment in the study and were put in the test arm. Based on this number, 65 healthy women were included in control arm.

All enrolled subjects were made to complete a questionnaire regarding demographic, reproductive, anthropometric and hormonal factors to assess for the presence or absence of the established risk factors in women diagnosed with carcinoma breast which formed the test group and women from the community which constituted the control group.

Risk factors being evaluated were: Obesity, early menarche, late menopause, age at eldest childbirth, parity, breast feeding, use of hormone replacement therapy (HRT), benign breast disease and family history.

Weight and height for all women were measured. Weight was measured to a nearest of 0.1 kilogram in light clothing and without shoes using standard weighing scales. Height was measured to a nearest of 0.5 centimetres without shoes using a steady wall mounted stadiometer. BMI was calculated using the formula: weight $(\mathrm{Kg}) /$ height $\left(\mathrm{m}^{2}\right)$. Presence of obesity was taken as a body mass index of $>30 \mathrm{Kg} / \mathrm{m}^{2}$ according to World Health Organization classification. Early menarche was taken as start of menstruation $<12$ years of age. Late menopause was taken as cessation of menstrual cycles after 55 years of age. Age more than 30 years at time of first childbirth was taken as a risk factor. Breast feeding of children was taken as a protective factor. Nulliparity, use of hormone replacement therapy, presence of any benign breast disease in the past and positive family history of carcinoma breast in first- or seconddegree blood relatives were taken as risk factors, whereas their negative counterparts were taken as protective factors in our study.

\section{Statistical Analysis}

Categorical variables were presented in number and percentage (\%) and continuous variables were presented as mean \pm standard deviation (SD) and median. Quantitative variables were compared using the t-test and significance was tested using the p-test.

Results were calculated by estimating the percentage of women in whom the established risk factors were present in both groups. A p-value of $<0.05$ was considered as significant. 
RESULTS

In the present study, test and control groups were equally matched with respect to age, educational status (uneducated or basic schooling vs higher education), occupation (employed versus unemployed), residence (rural vs urban) and dietary factors (vegetarian vs non-vegetarian), marital status (married vs unmarried), physical activity (regular physical activity vs sedentary lifestyle), use of oral contraceptive pills OCPs (yes vs no)

(Table 1).

\begin{tabular}{|c|c|c|c|}
\hline & Test Group $(n=65)$ & $\begin{array}{c}\text { Control Group } \\
(n=65)\end{array}$ & P-Value \\
\hline Mean range (in years) & $42-78$ & $40-79$ & \\
\hline Mean age & $57( \pm 11.27)$ & $56( \pm 11.04)$ & \\
\hline Body mass index (BMI) & & & $<0.002$ \\
\hline Mean BMI & $28.36 \mathrm{Kg} / \mathrm{m}^{2}$ & $24.32 \mathrm{Kg} / \mathrm{m}^{2}$ & \\
\hline$\geq 30$ & $12(18.4 \%)$ & $8(12.3 \%)$ & \\
\hline \multirow[t]{2}{*}{$<30$} & $53(81.5 \%)$ & $57(87.7 \%)$ & \\
\hline & Education & & 0.829 \\
\hline School & $46(70.8 \%)$ & $41(63.1 \%)$ & \\
\hline \multirow[t]{2}{*}{ College } & $19(29.2 \%)$ & $24(36.9 \%)$ & \\
\hline & Occupation & & 0.445 \\
\hline Unemployed & $47(72.3 \%)$ & $42(64.6 \%)$ & \\
\hline \multirow[t]{2}{*}{ Employed } & $18(27.7 \%)$ & $23(35.4 \%)$ & \\
\hline & Diet & & 0.588 \\
\hline Non-vegetarian & $23(35.4 \%)$ & $25(38.4 \%)$ & \\
\hline \multirow{2}{*}{ Vegetarian } & $42(64.6 \%)$ & $40(61.5 \%)$ & \\
\hline & Residence & & 0.370 \\
\hline Rural & $33(50.7 \%)$ & $37(56.9 \%)$ & \\
\hline \multirow[t]{2}{*}{ Urban } & $32(49.2 \%)$ & $28(43.1 \%)$ & \\
\hline & Marital Status & & 0.388 \\
\hline Unmarried & $4(6.1 \%)$ & $7(10.7 \%)$ & \\
\hline \multirow[t]{2}{*}{ Married } & $61(93.8 \%)$ & $58(89.2 \%)$ & \\
\hline & Physical activity & & 0.580 \\
\hline Regular exercise & $3(4.6 \%)$ & $7(10.7 \%)$ & \\
\hline \multirow{2}{*}{ No exercise/ routine work } & $62(95.4 \%)$ & $58(89.2 \%)$ & \\
\hline & Use of OCPs & & 0.277 \\
\hline Yes & $5(7.7 \%)$ & $4(6.1 \%)$ & \\
\hline \multirow[t]{2}{*}{ No } & $60(92.3 \%)$ & $61(93.8 \%)$ & \\
\hline & perestrogenic State & & 0.753 \\
\hline Yes & $4(6.1 \%)$ & $2(3.1 \%)$ & \\
\hline No & $61(93.8 \%)$ & $63(96.9 \%)$ & \\
\hline
\end{tabular}

Women chosen for the study were aged between 40-80 years. Mean age in test group was $57( \pm 11.27)$ years, while it was $56( \pm 11.04)$ years in the control group. Mean BMI for the test arm was $28.36 \mathrm{Kg} / \mathrm{m}^{2}$ compared to $24.32 \mathrm{Kg} / \mathrm{m}^{2}$ in the control arm. 12 patients (18.4\%) in the test group were found to be obese compared to 8 women $(12.3 \%)$ in the control group and this difference was found to be statistically significant ( $\mathrm{p}$ value $<0.002$ ).

Early menarche was seen in 16 patients $(24.6 \%)$ vs in 17 women $(26.1 \%)$ in control group. Late menopause was seen in 4 women $(6.1 \%)$ in both arms. 4 women $(6.1 \%)$ in test arm were nulliparous compared to 2 nulliparous women (3.1\%) in the control arm. Age at eldest childbirth was $>30$ years in 2 patients (3.1\%) vs 3 women (4.6\%) in control group. 6 women $(9.2 \%)$ in test arm had not breast fed their children, whereas, this number was $4(6.1 \%)$ in the control arm. Benign breast disease was previously present in $4(6.1 \%)$ patients of breast cancer in comparison with only 2 women (3.1\%) in control arm. Hormone replacement therapy was taken by only 2 (3.1\%) patients vs 1 healthy woman (1.2\%). Lastly, family history was positive in $3(4.6 \%)$ women suffering from breast cancer and 2 subjects (3.1\%) in control arm respectively.

This data was evaluated to assess for relevance. We found that there was no statistically significant difference between the two groups ( $p>0.05$ ) with respect to the established risk factors other than obesity.
Data is represented in the form of charts in Figures 1 and 2 .

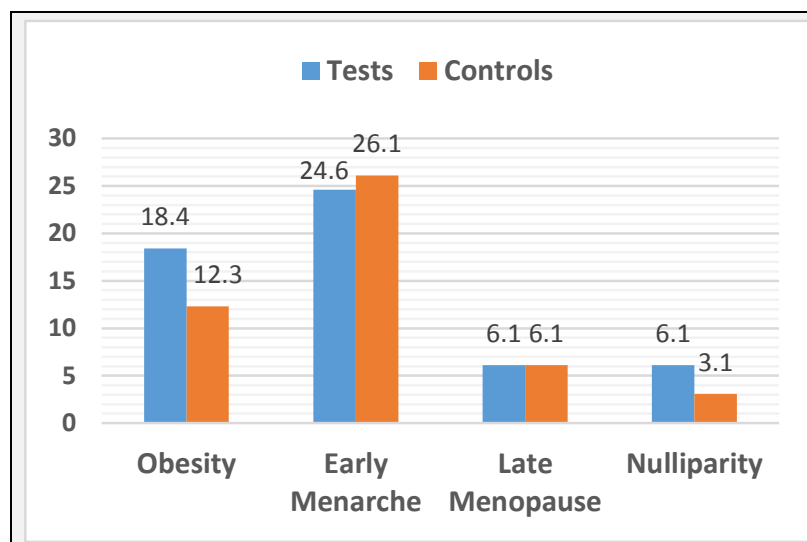

Figure 1. Percentage of Women in Test (Blue) and Control (Orange) Groups in Whom the Risk Factors were Present

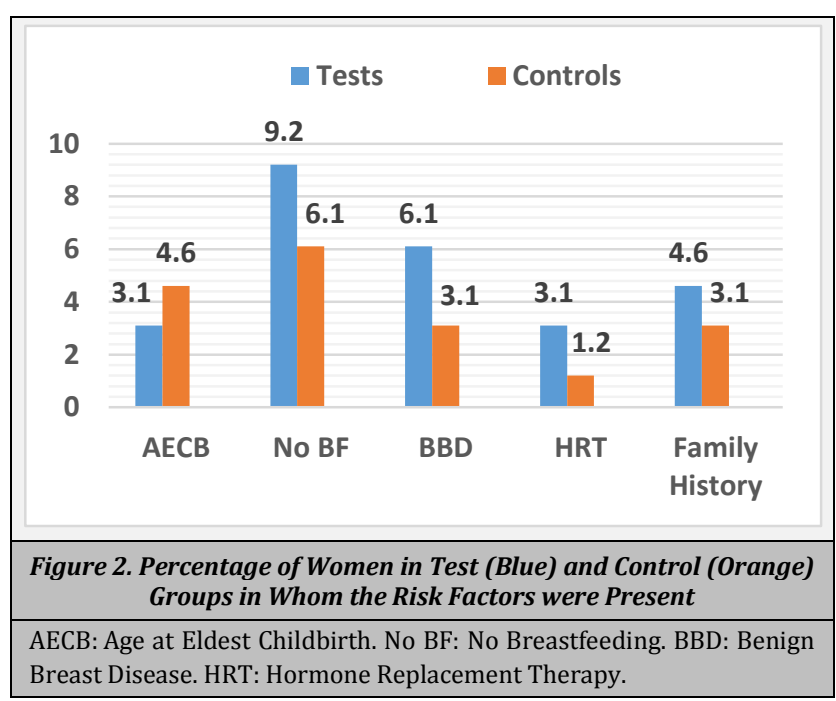

\section{DISCUSSION}

The present case control study conducted at a tertiary teaching hospital consisted of 65 women each in test and control group. The age at presentation ranged from 40 to 80 years. Palachandra et al, ${ }^{12}$ conducted a similar study in which women were aged between 24 to 74 years. Age at presentation ranged from 18-70 years in a similar study exploring the risk factors in Turkish women. ${ }^{13}$ In our study, majority of women in both arms (40 out of 130 i.e. $30.77 \%$ ) were in the age group of 61 70 years. The mean age at presentation was 57 years in the test group and 56 years in the control group. Meshram et al,14 reported a mean age at presentation of 48.9 years in a similar study conducted by them.

In the present study, it was observed that women with carcinoma breast had a strong association with obesity, as demonstrated by increased body mass index (BMI) levels of $\geq 30 \mathrm{Kg} / \mathrm{m}^{2}$. The percentage of obese women in test vs control arm was $18.4 \%$ vs $12.3 \%$ respectively ( $p<0.05$ ). Similar results were also observed in other similar studies conducted in India. ${ }^{15,16}$ Breast cancer incidence is known to be higher in obese women, especially in the post-menopausal age group. This has been attributed to higher oestrogen levels associated 
with increased adipose tissues and increased aromatase enzyme levels, causing more peripheral conversion of androgens to estradiol. Most studies conducted in the premenopausal age group, however, do not show a strong relation between breast cancer and higher BMI levels. Van der Brandt et al, ${ }^{17}$ conducted a pooled analysis of data from seven cohorts and concluded that BMI showed significant positive associations with breast cancer among pre-menopausal and post-menopausal women, respectively. Cheraghi et al, ${ }^{18}$ have also demonstrated similar outcomes.

The complex interaction between diet, physical activity and BMI may however complicate the interpretation of these results.

There was no significant association of breast cancer with early menarche ( $<12$ years) or to late menopause ( $>55$ years) in our study, but a relation has been seen in studies conducted by Murthy et al ${ }^{19}$ and Meshram et al. ${ }^{14}$

Helmrich et $\mathrm{al}^{20}$ reported significant association of increasing age at first childbirth with incidence of carcinoma breast. Delay in first childbirth as a risk factor could not be assessed as majority of the women in both test and control group had younger age at first childbirth. A possible explanation for this could be early age of marriage and hence early first childbirth in Indian women, especially in the age group studied by us.

The present study did not show any association between breast feeding as most of the women breast fed their children to a minimum of one year. Palachandra et al, ${ }^{12}$ could not demonstrate any association with lactation in their study.

Relation between parity and breast cancer was not established in our study in consensus. A similar study by Wrensch et al, ${ }^{21}$ showed a significant association of breast cancer with parity.

There was no association between benign breast disease, use of hormone replacement therapy and family history, to breast cancer in the present study. One of the reasons for these factors not showing up any relation with disease causation in our study could be an ineffective sample size. Also, most Indian women are alien to the concept of use of HRT for postmenopausal symptoms.

Various studies such as Gajalakshmi et al,22 have reported increased incidence of carcinoma breast in women with higher education. Rai et al, have reported association of carcinoma breast with higher education and higher socio-economic status. In the present study, factors such as education, occupation, diet, residence, physical activity, marital status and use of oral contraceptives were not studied for their association with the disease as most studies in western world have included them in the category of probable or possible risk factors, than established risk factors.

Breast cancer is a major cause of morbidity and mortality among women. In the present study, we concluded that while the established risk factors for carcinoma breast have been found to be relevant in multiple national and international studies, their applicability to specific populations such as those catered to by our institution varied.

Out of all the established risk factors for carcinoma breast in the western population, the present study suggested significance only for obesity, with a BMI of $\geq 30 \mathrm{Kg} / \mathrm{m}^{2}$. This study, however, opens up future avenue of research where the association of breast cancer to waist-to-hip ratio and a body shape index (ABSI) can be further explored in Indian women.
These parameters are better indicators of obesity as compared to BMI as they give clearer idea about sites of fat distribution in body and indicate towards central obesity.

Although epidemiology of breast cancer shows an increasing trend for incidence and mortality in various parts of India especially metropolitan cities, more evaluation is required for establishing more affirmative association of these risk factors in our population. Cancer projection data shows that by 2020 , the number of women suffering from carcinoma breast will approximately double. Hence it is all the more relevant to identify women at higher risk and screen them for the purpose of early detection and treatment. Women with non-modifiable risk factors can especially be screened and high-risk populations be identified.

It was also observed in our study that a delay between observation of first clinical symptoms and presentation to hospital for purpose of treatment was present in more than $80 \%$ of patients. Most important reasons for this delay were illiteracy, lack of awareness about cancer symptoms, an attitude of general indifference towards health in women and lack of adequate medical facilities. This results in presentation of people at an advanced disease stage and hence poorer outcome and greater mortality.

\section{CONCLUSIONS}

While the established risk factors for carcinoma breast have been found to be relevant in multiple national and international studies, their applicability to specific populations such as those catered to by our institution varied. Out of all the established risk factors for carcinoma breast in the western population, the present study suggested significance only for obesity, with a BMI of $\geq 30 \mathrm{Kg} / \mathrm{m}^{2}$

Future studies to explore the risk factors relevant to Indian women are needed as most of the established risk factors found in women suffering from breast cancer in the western world were not present in the cohort studied. Larger epidemiological studies would guide us in finding out the risk factors for breast cancer in Indian women.

Financial or Other Competing Interests: None.

\section{REFERENCES}

[1] Bray F, Ferlay J, Soerjomataram I, et al. Global cancer statistics 2018: GLOBOCAN estimates of incidence and mortality worldwide for 36 cancers in 185 countries. CA Cancer J Clin 2018;68(6):394-424.

[2] Benson JR, Jatoi I. The global breast cancer burden. Future Oncol 2012;8(6):697-702.

[3] Ferlay J, Soerjomataram I, Dikshit R, et al. Cancer incidence and mortality worldwide: sources, methods and major patterns in GLOBOCAN 2012. Int J Cancer 2015;136(5):E359-86.

[4] Ahmad A. Breast Cancer statistics: recent trends. In: Ahmad A, ed. Breast cancer metastasis and drug resistance. Springer 2019:1-7. 
[5] Nguyen J, Le QH, Duong BH, et al. A matched case-control study of risk factors for breast cancer risk in Vietnam. Int J Breast Cancer 2016;2016:1-7.

[6] Bray F, McCarron P, Parkin DM. The changing global patterns of female breast cancer incidence and mortality. Breast Cancer Res 2004;6(6):229-39.

[7] Youlden DR, Cramb SM, Yip CH, et al. Incidence and mortality of female breast cancer in the Asia-Pacific region. Cancer Biol Med 2014;11(2):101-15.

[8] Bray F. Transitions in human development and the global cancer burden. World Cancer Report 2014:54-68.

[9] Malvia S, Bagadi SA, Dubey US, et al. Epidemiology of breast cancer in Indian women. Asia Pac J Clin Oncol 2017;13(4):289-95.

[10] Fernley J, Shin HR, Forman D, et al. Estimates of Worldwide Burden of Cancer in 2008: GLOBOCAN 2008. Int J Cancer 2010;127(12):2893-917.

[11] McPherson K, Steel CM, Dixon JM. ABC of breast diseases. Breast cancer-epidemiology, risk factors, and genetics. $\mathrm{Br}$ Med J 2000;321(7261):624-8.

[12] Palachandra A, Ishwaraprasad GD, Sreelatha CY, et al. Risk factors associated with carcinoma breast: a case control study. Int Surg J 2017;4(9):3136-40.

[13] Ozmen V, Ozcinar B, Karanlik H, et al. Breast cancer risk factors in Turkish women--a University Hospital based nested case control study. World J Surg Oncol 2009;7:37.

[14] Meshram II, Hiwarkar PA, Kulkarni PN. Reproductive risk factors for breast cancer: a case control study. Online Journal of Health and Allied Sciences 2009;8(3).
[15] Malvia S, Bagadi SA, Dubey US, et al. Epidemiology of breast cancer in Indian women. Asia Pac J Clin Oncol 2017;13(4):289-95.

[16] Pakseresht S, Ingle GK, Bahadur AK, et al. Risk factors with breast cancer among women in Delhi. Indian J Cancer 2009;46(2):132-8.

[17] van den Brandt PA, Spiegelman D, Yaun SS, et al. Pooled analysis of prospective cohort studies on height, weight, and breast cancer risk. Am J Epidemiol 2000;152(6):51427.

[18] Cheraghi Z, Poorolajal J, Hashem T, et al. Effect of body mass index on breast cancer during premenopausal and postmenopausal periods: a meta-analysis. PloS One 2012;7(12):e51446.

[19] Murthy NS, Agarwal UK, Chaudhry K, et al. A study on time trends in incidence of breast cancer-Indian scenario. Eur J Cancer Care (Engl) 2007;16(2):185-6.

[20] Helmrich SP, Shapiro S, Rosenberg L, et al. Risk factors for breast cancer. Am J Epidemiol 1983;117(1):35-45.

[21] Wrensch M, Chew T, Farren G, et al. Risk factors for breast cancer in a population with high incidence rates. Breast Cancer Res 2003;5(4):R88-102.

[22] Gajalakshmi CK, Shanta V. Risk factors for female breast cancer a hospital-based case-control study in Madras, India. Acta Oncol 1991;30(5):569-74. 